\title{
El solve et repete en el ambiente tributario. Apuntes críticos en torno a las tesis que justifican su exigencia
}

\author{
Solve et repete in the Tax \\ Environment. Critical Notes on the \\ Theses Justifying Its Demand
}

\author{
Solve et repete no ambiente \\ tributário. Notas críticas em torno das \\ teses que justificam sua demanda
}

Yaneisi Bencomo Fariñas*

https://orcid.org/0000-0001-6022-6042. Universidad de Pinar del Río “Hermanos Saíz Montes de Oca", Cuba. yaneisi@upr.edu.cu 


\section{Resumen}

En el presente trabajo se exponen argumentos que detractan el sostenimiento, en la actualidad, de una de las más reconocidas reglas procesales en el campo del derecho tributario: el solve et repete o pago previo. El objetivo es realizar una valoración crítica de las diferentes tesis que se han defendido en la doctrina para justificar la exigencia de este requerimiento económico en el panorama tributario, y se reflexiona en torno a sus insuficiencias. De forma paralela, se enfatiza en la necesidad de que cada Estado, al instituir las potestades y prerrogativas de la administración tributaria, garantice que estas no atenten contra el irrestricto respeto, aseguramiento y defensa de los derechos de los obligados tributarios -en particular de los contribuyentes-; en tanto los derechos se erigen en fin y límites constitucionales del ejercicio del poder estatal y de las competencias de los gobernantes y órganos del poder público.

\section{Palabras clave}

Pago previo; solve et repete; naturaleza jurídica; tesis; administración tributaria; contribuyentes; derechos. 


\section{Abstract}

This paper presents arguments against the maintenance of one of the most recognized procedural rules in tax law: solve et repete or prepayment. So, the objective is to make a critical assessment of the different theses defended by the doctrine to justify this economic requirement in the tax landscape, reflecting on its inadequacies. In parallel, it emphasizes the need for each State to guarantee, when instituting the powers and prerogatives of the Tax Administration, that they do not violate the unrestricted respect for, assurance, and defense of the taxpayers' rights, in as much the rights are established within the constitutional limits and purposes of state power and the jurisdictions of rulers and government agencies.

\section{Keywords}

Prepayment; solve et repete; legal nature; thesis; tax administration; taxpayers; rights. 


\section{Resumo}

No presente trabalho, são apresentados argumentos que desvirtuam o suporte, na atualidade, de uma das regras processuais mais reconhecidas no campo do Direito Tributário: a solve et repete ou pagamento antecipado. Para tanto, objetiva-se fazer uma avaliação crítica das diferentes teses defendidas na doutrina para justificar a exigência desse requisito econômico no cenário tributário, refletindo sobre suas inadequações. Paralelamente, destaca-se a necessidade de cada Estado, ao instituir os poderes e as prerrogativas da Administração Tributária, garantir que eles não violem o respeito irrestrito, a garantia e a defesa dos direitos dos contribuintes - em particular dos contribuintes -; enquanto os direitos são elevados em ordem e limites constitucionais do exercício do poder estatal e das concorrências dos governantes e dos órgãos do poder público.

\section{Palavras-chave}

Pagamento antecipado; solve et repete; natureza jurídica; tese; administração tributária; contribuintes; direitos. 
Sumario: Introducción. 1. Fundamentos teóricos del solve et repete en el ámbito tributario. 1.1. tesis sobre la naturaleza jurídica y aplicabilidad del solve et repete. 1.1.1. Tesis política.1.1.2. Tesis fiscal o tributarista.1.1.3. Tesis iusprocesalista o prejudicial. 1.1.4. Tesis administrativista. 1.1.5. Tesis autónoma. 1.1.6. Unión de dos o más tesis. 2. La regla solve et repete y su incidencia en derechos y principios constitucionalmente reconocidos. Conclusiones. Bibliografía.

\section{Introducción}

La relación jurídico-tributaria se manifiesta, en la mayoría de las ocasiones, como una relación conflictiva en la que la Administración Tributaria cuenta con privilegios a los efectos de proteger la rápida percepción del crédito fiscal. Además del interés general que media como justificación para la exigencia de tales privilegios, se invocan como fundamentos la presunción de legitimidad de la pretensión estatal, así como la ejecutoriedad de los actos administrativos. ${ }^{1}$ Sin embargo, se nos puede presentar el problema de que tales prerrogativas, como ocurre con el solve et repete, ${ }^{2}$ puedan llegar a afectar derechos humanos. Aun cuando esta figura ha motivado un mayoritario rechazo en la doctrina, ${ }^{3} \mathrm{y}$ ha sido incluso eliminada de la normativa tributaria por varios países y reputada inconstitucional, ${ }^{4}$ aún sigue vigente en algunos ordenamientos jurídicos.

1 Yaneisi Bencomo Fariñas, "Solve et repete vs. tutela judicial en Cuba: tema pendiente en el Derecho Procesal Constitucional", Revista Mexicana de Derecho Constitucional Cuestiones Constitucionales 28 (2013), p. 6.

2 Locución latina que puede ser traducida como "paga y reclama", y que significa para el contribuyente que impugna un acto administrativo tributario -que implique la obligación del pago de un crédito-, la carga del pago previo del referido monto para tener derecho a interponer el correspondiente recurso en proceso administrativo como vía previa necesaria para poder ulteriormente instar en sede judicial.

3 Entiende Valdés Costa que el solve et repete es "un criticable y criticado privilegio cuya supervivencia solo se explica como producto de la rutina y de la falta de estudios serios sobre el tema" (Ramón Valdés Costa, El contencioso tributario (Comunicación presentada a las "Segundas Jornadas Latinoamericanas de Derecho Tributario", efectuadas en México, D.F, en octubre de 1958), p. 53, en http://www.google.com.cu/search?q=Ram\%C3\%B3n+ Vald $\% \mathrm{C} 3 \% \mathrm{~A} 9 \mathrm{~s}+\mathrm{Costa} \% 3 \mathrm{~A}+\mathrm{El}+$ contencioso+administrativ\&ie=utf-8\&oe=utf8\&aq=t\&rls=org.mozilla:esES:official\&client=firefox-a, consultado el 15 de marzo de 2012. Tan es así que, según Villegas, esta regla "dista de ser indiscutidamente aceptada por la doctrina", tomando como ejemplo para aseverar esta idea tres pronunciamientos categóricos y de indudable jerarquía científica contra el solve et repete señalados por Valdés Costa: el emitido en las Primeras Jornadas Latinoamericanas de Derecho Procesal, celebradas en Montevideo en 1957, donde se resolvió que "ninguna norma debe establecer el pago previo de las prestaciones reclamadas por la Administración como requisito para el ejercicio de recursos administrativos y de la acción de nulidad". El emitido en las Segundas Jornadas Latinoamericanas de Derecho Tributario, celebradas en México en 1958, al tratarse su número 2 referido al Proceso Contencioso-Tributario, se adoptó como recomendación que debía "ser eliminado como requisito de procedencia, tanto para la interposición de recursos administrativos, como en el ejercicio de la acción contenciosa, el pago previo de los tributos, sin perjuicio de las garantías que fueran necesarias para los casos de riesgo de incumplimiento del crédito fiscal". El emitido en las Jornadas LusoHispano-Americanas de Pamplona, en 1976, en las que se sostuvo en el numeral 16 que "la interposición y decisión de recursos o acciones no debe estar condicionada al pago previo de la obligación impugnada, ni a ningún otro requisito que no tenga relación directa con el objeto del recurso o acción que se deduce" (Héctor B. Villegas, Curso de finanzas, derecho financiero y tributario, 7 ed., ampliada y actualizada, Buenos Aires, Ediciones Depalma, 2001, p. 505).

4 Los ejemplos que permiten corroborar estas apreciaciones son diversos. En Italia, la regla fue derogada por declaración de inconstitucionalidad de la Corte Constitucional el 31 de marzo de 1961. España fue otro país en el que el solve et repete sufrió la misma tacha de inconstitucionalidad conforme a la sentencia del Tribunal Supremo en fecha 14 de junio de 1973, reafirmada luego por la interpretación brindada a la Constitución reformada de 1978, especialmente en su artículo 24. En Uruguay, la Suprema Corte de Justicia mantiene una jurisprudencia firme en el sentido de que el solve et repete es inconstitucional, por Sentencia 75 del 20 de mayo de 1959. En Ecuador, en el año 1975 entró en vigencia el Código Tributario, y con él se puso fin a la regla solve et repete, derogatoria que representaba uno de los principales objetivos para la comisión redactora del Código. En Venezuela, la entonces Sala Político-Administrativa de la Corte Suprema, en Sentencia del 14 de octubre 
De tal modo, como acertadamente nos alerta Santamaría Pastor, el solve et repete no ha muerto en la legislación, en la doctrina jurisprudencial ni, lo que es peor, en las aficiones y los reflejos instintivos de una burocracia que se aferra con desesperación a los más deprimentes privilegios. ${ }^{5}$

Así, es una realidad cómo actualmente las legislaciones tributarias internas de algunos países continúan contemplando la exigencia de este pago previo. En el derecho latinoamericano se pueden advertir varios ejemplos. Tal es el caso de Cuba, donde siguiendo la tradición fiscal heredada, el requerimiento del solve et repete es exigible durante la vía administrativa solo al momento de interponer el recurso de alzada, como queda consignado sustantivamente en el artículo 467 de la Ley 113 del Sistema Tributario, de 23 de julio de $2012^{6}$ y en el artículo 193 de su Reglamento. ${ }^{7}$ En Argentina, el solve et repete fue incorporado por la jurisprudencia de la Corte Suprema de Justicia de la Nación; en Buenos Aires, en particular, el artículo noveno del Código Contencioso Administrativo y Tributario introduce esta figura. ${ }^{8}$ En Perú, por su parte, resulta exigible el pago previo en el proceso de las reclamaciones del impuesto a la renta. En el caso mexicano, la Ley Federal de Procedimiento Administrativo del Estado de México, la Ley de Amparo, reglamentaria de los artículos 103 y 107 de la Constitución Política de los Estados Unidos Mexicanos ${ }^{9}$ y el Código Fiscal de la Federación, incluyen al solve et repete; específicamente, la Ley Federal de Procedimiento Administrativo, ${ }^{10}$ en su artículo 87. En Chile, diferentes cuerpos normativos contienen la exigencia de este requerimiento económico, como es el caso de la Ley Orgánica Constitucional del Banco Central de Chile, ${ }^{11}$ Ley 19.300 sobre bases Generales del Medio Ambiente ${ }^{12}$, Ley $19.613^{13}$ sobre legislación eléctrica, entre otras.

Lamentablemente, estos son solo algunos ejemplos de países en los que continúa vigente el solve et repete, cuya aplicación conduce a que el obligado tenga que desembolsar una deuda tributaria frente a un valor reclamable $y$, aun asistido de razón, deba una determinada suma de dinero para ejercer su derecho a la defensa y poder oponerse en el proceso administrativo ante la Administración Tributaria y hasta el poder judicial. De carecer entonces de los recursos monetarios exigidos, se sitúa el contribuyente en un verdadero

de 1990, declaró, por vía de control difuso de constitucionalidad, la inconstitucionalidad del solve et repete por violación del derecho a la defensa.

5 Juan Santamaría Pastor, "Un paso adelante en la extinción del solve et repete", Revista Española de Derecho Administrativo 2 (1974), p. 311.

Publicada en Gaceta Oficial Ordinaria 53 de 21 de noviembre de 2012.

7 Decreto 308 Reglamento de las Normas Generales y de los procedimientos Tributarios, de 31 de octubre de 2012 (publicado en Gaceta Oficial Ordinaria 53 de 21 de noviembre de 2012).

8 Ley 189, Código Contencioso Administrativo y Tributario de la Ciudad Autónoma de Buenos Aires.

9 Ley de Amparo, reglamentaria de los artículos 103 y 107 de la Constitución Política de los Estados Unidos Mexicanos (DOF 10/01/1936).

44610 Ley Federal de Procedimiento Administrativo del Estado de México (DOF 04/08/1994).

11 Ley 18.840 del Banco Central Chile, 10/10/1989.

12 Ley 19.300 sobre Bases Generales del Medio Ambiente (09/03/1994).

13 Ley 19.613 de modificación de la Ley 18.410, orgánica de la superintendencia de electricidad y combustibles. 
estado de indefensión. Esta situación nos impone un imperativo: lograr una mayor protección jurídica del sujeto pasivo en la relación jurídico-tributaria, en aras de conferirle seguridad jurídica frente a los actos desarrollados por la Administración Pública en la esfera fiscal.

Debemos tener siempre presente que el acceso a la justicia no puede quedar condicionado a la posesión de medios económicos, que es exactamente en lo que consiste el solve et repete. En otras palabras, no sería admisible actualmente seguir reconociendo esta amplia gama de potestades exorbitantes de la Administración del Estado, sin que, por otra parte, se habilitaran mecanismos efectivos de control y garantía de los derechos de los ciudadanos frente al poder. En efecto, tal y como ha aseverado Rodríguez Bereijo,

las potestades que el ordenamiento confiere a la Administración Tributaria no dan a esta unas facultades ilimitadas en su actividad inspectora y liquidadora [...] Se trata en todo caso de potestades tasadas en su contenido y en su finalidad, cuya correcta utilización es susceptible de control jurisdiccional ante los Tribunales de Justicia en garantía de los derechos de los contribuyentes. ${ }^{14}$

Y es que los derechos se erigen en basamento sine qua non para la existencia democrática-institucional de cualquier país; es a través de ellos que los valores rectores éticos y políticos de la sociedad alcanzan expresión jurídica. A la par, los derechos constituyen preceptos directamente vinculantes y aplicables; de ahí que deban impregnar todos y cada uno de los sectores del ordenamiento jurídico; el Derecho Tributario no es la excepción.

La eficacia jurídica de los derechos de los contribuyentes dependerá, pues, de las posibilidades reales de ejercicio y de la protección con que cuenten dentro del ordenamiento jurídico, y su concreción material está directamente relacionada con las condiciones sociales, económicas y políticas que se les brinden. En este sentido, la configuración adecuada de las potestades exorbitantes de la Administración y su control, para que no devengan en arbitrarias, exigen un sistema eficaz de justicia administrativa, sin la cual no está plenamente asegurado el Estado de derecho.

Sobre la base de los argumentos aportados a priori es que se fundamenta la relevancia del presente trabajo, cuyo objetivo se centra, en la realización de una valoración crítica de las diferentes tesis que se han defendido en la doctrina para justificar la exigencia de este requerimiento económico en el panorama tributario, a partir de una reflexión en torno a sus insuficiencias. Ello permitirá analizar, además, las implicaciones prácticas que tal figura presenta, toda vez que afecta al obligado tributario y a la Administración en su condición de garante del interés público.

14 Álvaro Rodríguez Bereijo, "El sistema tributario en la Constitución. (Los límites del poder tributario en la jurisprudencia del Tribunal Constitucional)", Revista Española de Derecho Constitucional, Año 12 (36) (1992), p. 66. 
A ello se adiciona el momento histórico por el que cursa el derecho tributario en el mundo, convocado a dejar atrás la concepción autoritaria del tributo, a perfeccionar su procedimiento de gestión, con una política tributaria caracterizada por la sencillez de las normas, procedimientos y trámites tributarios, en el que la instrumentación de un sistema de garantías para lograr el sometimiento de la Administración Tributaria al ordenamiento jurídico, el despojo de ciertas prerrogativas y la necesaria justiciabilidad de los actos de la Administración Tributaria, continúan siendo hoy una asignatura pendiente.

\section{Fundamentos teóricos del solve et repete en el ámbito tributario}

Cuando se analiza el tratamiento que ha recibido el solve te repete en la doctrina, lo primero que nos salta a la vista es la multiplicidad de calificativos que le han atribuido los estudiosos del tema en un intento de desentrañar su naturaleza jurídica, al referirse indistintamente al pago previo como regla ${ }^{15} \mathrm{o}$ principio, ${ }^{16} \mathrm{y}$, en ocasiones, como privilegio. ${ }^{17}$

Sin ánimo de pretender aportar criterios acabados o definitivos en relación con la distinción entre estas categorías, lo cual conllevaría una nueva investigación que, por supuesto, sobrepasa la presente, sí trataremos de establecer ciertas base ${ }^{18}$ que nos permitirán aproximarnos al debate que en torno al tema se ha suscitado y así poder llegar a comprender mejor la esencia misma de la exigencia del pago previo.

Sobre la distinción entre principios y reglas hay dos criterios bastante delimitados, y son los que defienden, por una parte, Alexy y, por otra, Atienza y Ruiz Manero. ${ }^{19}$

Alexy sostiene que

15 Lo califican de regla autores como Héctor B. Villegas, Curso de Finanzas, Derecho Financiero y Tributario, 7 ed., Buenos Aires, Depalma, 2001, p. 461; Rafael Bielsa, Estudios de derecho público, t. II, Derecho fiscal, Buenos Aires, Depalma,1951, p. 325; Giorgio Tesoro, Principi di diritto tributario, Bari, 1938, p. 437; A. D. Giannini, Instituciones de Derecho Tributario, Madrid, Editorial de Derecho Financiero, 1957, p. 259; Rafael Mendizábal Allende, "Significado actual del principio 'solve et repete"”, Revista de Administración Pública 43 (1964), p. 107; José M. Martín Oviedo, "La decadencia de la regla solve et repete y la doctrina del Consejo de Estado", Revista de Administración Pública 43 (1964), pp. 151-152; etc.

16 Como principio la catalogan Dino Jarach, Estudios de derecho tributario, 3 ed., Buenos Aires, Abeledo-Perrot, 1998, p. 282; Benvenuto Griziotti, Principios de ciencia de las finanzas, Buenos Aires, Depalma, 1959, p. 50); entre otros.

17 Por su parte, le atribuyen la condición de privilegio (económico o procesal) autores como Cristian Billardi, Solve et Repete. Crítica a su vigencia jurídica, Argentina, Ad-Hoc, 2006, p. 104; Carlos M. Giuliani Fonrouge, Derecho financiero, Buenos Aires, Depalma, 3 ed., 1976, pp. 733-737; J. Santamaría Pastor, “Un paso adelante en la extinción del solve et repete", Revista Española de Derecho Administrativo 2 (1974), p. 311; Juan C. Ferrada Bórquez, "Las potestades y privilegios de la Administración Pública en el régimen administrativo chileno", Revista de Derecho XX (2) (2007), p. 84; Luis Cosculluela Montaner, Manual de Derecho Administrativo, t. I, 17 ed.,

448 Pamplona, Aranzadi, 2006, pp. 352-353; y otros.

18 Liana Simón Otero, "Los principios de justicia tributaria en la historia constitucional cubana", Revista Mexicana de Derecho Constitucional. Cuestiones Constitucionales 25 (2011), p. 204.

19 Ibid., p. 204. 
... el punto decisivo para la distinción entre reglas y principios es que los principios son normas que ordenan que se realice algo en la mayor medida posible, en relación con las posibilidades jurídicas y fácticas. Los principios son, por consiguiente, mandatos de optimización que se caracterizan porque pueden ser cumplidos en diversos grados y porque la medida ordenada de su cumplimiento no solo depende de las posibilidades fácticas, sino también de las posibilidades jurídicas [...] En cambio, las reglas son normas que exigen un cumplimiento pleno $\mathrm{y}$, en esa medida, pueden siempre ser solo o cumplidas o incumplidas. ${ }^{20}$

Atienza y Ruiz Manero critican esta concepción, teniendo en cuenta que hay principios en sentido estricto a los cuales no se les puede aplicar esta teoría, porque su cumplimiento no puede producirse en diversos grados, sino que se cumplen o no.

La diferencia estriba en que los principios configuran el caso de forma abierta, mientras que las reglas lo hacen de forma cerrada. Con ello se quiere decir que mientras que en las reglas las propiedades que conforman el caso constituyen un conjunto cerrado, en los principios no puede formularse una lista cerrada de las mismas: no se trata solo de que las propiedades que constituyen las condiciones de aplicación tengan una periferia mayor o menor de vaguedad, sino de que tales condiciones no se encuentran siquiera genéricamente determinadas. ${ }^{21}$

Aun cuando partimos de considerar que los dos criterios no son excluyentes, ni errados, sí reconocemos que la distinción establecida por Atienza y Ruiz Manero es determinante, pues el criterio de distinción del que parte Alexy puede tender a confusión cuando analizamos determinados principios, por lo que no nos ofrece claridad para diferenciarlos de las reglas, las que sí van a ser o cumplidas o no, siempre. ${ }^{22}$ De tal forma "los principios son normas que carecen de hipótesis jurídica, es decir, las circunstancias que deben darse para su aplicación a un caso concreto no están delimitadas en un marco cerrado de condiciones, todo lo contrario a lo que ocurre con las reglas" ${ }^{23}$

Aunque algunos autores defienden hoy la idea de que cuando del solve et repete se trata estamos ante un principio en el sentido jurídico del término, consideramos que se configura, en el ámbito fiscal, como regla, toda vez que en su propio enunciado quedan establecidas de forma expresa y cerrada las condiciones que deben darse para su exigencia. ${ }^{24}$ Así, cuando el contribuyen-

20 Robert Alexy, "Sistema jurídico. Principios jurídicos y razón práctica”, Revista Doxa 5 (1988), p. 143.

21 Manuel Atienza y Juan Ruiz Manero, "Sobre principios y reglas", Revista Doxa 10 (1991), p. 108.

22 Simón Otero, "Los principios de justicia tributaria", op., cit., p. 205.

23 Liana Simón Otero, La protección del contribuyente en Cuba: una visión desde el derecho constitucional tributario (tesis presentada en opción al título académico de Máster en Derecho Constitucional y Administrativo), La Habana, 2011, p. 22.

24 Mendizábal Allende centró su atención en este debate, e hizo constar expresamente que "la regla solve et repete carece de todo fundamento filosófico, técnico o científico, excluyéndose así, automáticamente, la posibilidad de calificarla como un auténtico principio jurídico" (Mendizábal Allende, "Significado actual del principio 'solve et repete'"', op. cit., pp. 108-110). Coincidiendo con esta postura se pronuncia Hutchinson, para quien al no poder catalogarse al solve et repete dentro de ninguna de las categorías de los principios generales, este carece de carácter de principio. Asimismo, distingue que "no encaja tampoco dentro del concepto de privilegio, 
te reclame un acto administrativo/tributario que incluya el desembolso de un crédito, resultará necesario su pago previo para poder recurrir, ya sea en la propia fase administrativa o para iniciar un proceso ante la jurisdicción contencioso-administrativa. Estamos, pues, ante una regla de carácter procesal, que condiciona el inicio del proceso al previo ingreso en calidad de depósito de la cantidad adeudada por el contribuyente o a él reclamada.

Si bien no ha existido consenso en la doctrina en cuanto a la naturaleza jurídica, sí ha sido manifiesta y casi general la hostilidad contra la perduración de la regla solve et repete al erigirse en verdadero obstáculo para el contribuyente, pues le limita la posibilidad de recurrir los actos de la Administración Tributaria, tanto en sede administrativa como judicial, ${ }^{25}$ lo que constituye así, desde su origen, "un medio utilizado frecuentemente para encubrir la arbitrariedad administrativa y hacer ilusoria la defensa del contribuyente" ${ }^{26}$

Empero, ¿cuáles han sido, entonces, las razones o los motivos que se han defendido para justificar el reconocimiento y la consecuente aplicación de esta regla? Argüir sobre este particular trae consigo analizar los diversos fundamentos invocados por estudiosos del tema, que van desde los relacionados con ciertos principios administrativistas hasta otros de dudosa juridicidad.

\subsection{Tesis sobre la naturaleza jurídica y aplicabilidad del solve et repete}

\subsubsection{Tesis política}

Esta teoría, de fundamento esencialmente político, parte de concebir al solve et repete como un privilegio del Estado, particularmente del fisco, instituido con una finalidad de orden práctico, consistente en impedir que la actividad estatal se vea perturbada por demoras durante la recaudación tributaria. Para quienes sostienen esta tesis, el hecho de reconocer y permitir a los contribuyentes la posibilidad de discutir la procedencia o no de la deuda tributaria determinada administrativamente sin el requisito del pago previo, traería consigo una afectación evidente al Estado, pues la impugnación de los actos administrativos a través de la interposición de recursos podría dilatar el expedito ingreso de fondos al erario, y, con ello, se estaría afectando el sostenimiento de los gastos públicos y la consecuente satisfacción de los intereses generales.

ya que solo se llama privilegio a aquella disposición jurídica creadora, de modo inmediato, de una situación jurídica concreta"; concluye, entonces, que el pago previo "es una regla jurídica de carácter procesal" (Tomás Hutchinson, "El solve et repete en la Argentina (con especial referencia al Código Tributario de la Ciudad Autónoma de Buenos Aires)", Revista de Derecho Público, abril-junio (2003), p. 380.

$450 \quad 25$ Bencomo Fariñas, "Solve et repete vs. tutela judicial en Cuba", op. cit., p. 31.

26 Carlos Giuliani Fonrouge, Rubens Gómez De Sousa y Ramón Valdés Costa, Reforma Tributaria para América Latina III Modelo de Código Tributario, Washington D.C., Unión Panamericana Secretaría General, Organización de los Estados Americanos, 1968, p. 124. 
Sobre esta interpretación política de la regla se han pronunciado varios autores. Zingali, por ejemplo, resume su contenido al manifestar que "el pago previo se considera únicamente como el medio del que se vale el ente público para realizar puntualmente sus ingresos y para desbaratar la táctica dilatoria de los contribuyentes astutos, dispuestos a perturbar la justicia, con tal de retrasar el pago" ${ }^{27}$ Jarach, por su parte, nos perfila el fin práctico de esta regla: "la obtención, a cualquier costo, del ingreso tributario previsto, sin que esté subordinado a excepciones dilatorias o a suspensiones del procedimiento ejecutivo con grave daño para el funcionamiento del aparato estatal" ${ }^{28}$

Aun cuando han sido varios los seguidores de esta tesis, no se puede afirmar que la misma haya estado alejada de fuertes críticas. Según Giuliani Fonrouge, "este privilegio del fisco no resulta imprescindible si lo que se quiere es asegurar el interés fiscal, poniéndolo a cubierto de malévolas argucias y expedientes dilatorios; finalidad esta que se puede obtener por otros medios, sin necesidad de recurrir a un medio justamente condenado como inicuo instrumento de tortura, llamado a desaparecer". ${ }^{29}$

Calificamos, pues, de insatisfactorio el fundamento político que pretende otorgarle esta tesis al solve et repete, y no debe el Estado hacer uso de tal regla con el pretexto de la necesidad de evitar que los contribuyentes, al impugnar los actos administrativos/tributarios por medio de la interposición de los recursos conferidos por ley, obstaculicen la normal y regular percepción de la renta pública. Ciertamente, el Estado no puede paralizar el procedimiento de gestión de los tributos, pues de ello depende en gran medida que cumpla con sus fines, que son básicamente la educación, la salud, la seguridad de toda la población, etc. Es también cierto que con la exigencia del pago previo se está ejerciendo sobre el deudor tributario una presión para constreñirlo, también

27 Martín Oviedo, “La decadencia de la regla de la regla solve et repete y la doctrina del Consejo de Estado", op. cit., p. 153. En opinión de este autor, junto a esta interpretación política se podría colocar la interpretación pragmática de la misma, destacada por Mendizábal, quien refiere que esta regla "actúa en defensa de los intereses inmediatos de la Administración Pública, contemplados con una mirada miope y sin trascendentalismo alguno" (Mendizábal Allende, "Significado actual del principio 'solve et repete"', op. cit., p. 153).

28 Jarach, Estudios de derecho tributario, op. cit., p. 242.

29 Carlos M. Giuliani Fonrouge, Derecho financiero, op. cit., p. 737. En este orden, Martín Oviedo apunta que "al Estado le conviene que su actividad no se detenga, a pesar de los ardides de sus deudores [...], solo que ocurre que en nuestros días existen otros procedimientos tan eficaces y más justos para lograr tal deseo" (Martín Oviedo, "La decadencia de la regla de la regla solve et repete y la doctrina del Consejo de Estado", op. cit., p. 155). Sobre estos medios o procedimientos que se pueden utilizar y que permiten lograr que ambas partes de la relación tributaria tengan una adecuada protección a sus derechos tanto, de acceder a la justicia (contribuyente), como el de asegurar su crédito (Estado), se pronunció Rosso, aludiendo al respecto dos soluciones: "la primera, receptada por países como Francia, Alemania y Uruguay, consistente en la suspensión de la ejecución fiscal una vez finalizada la etapa administrativa, por pedido del contribuyente, con la consiguiente constitución de garantías a favor de la Administración. La otra alude a que, una vez admitida la demanda, el juez, de acuerdo a la capacidad contributiva de cada contribuyente y a lo claro de su reclamo, establezca una justa y adecuada caución para asegurar que la pretensión del contribuyente es seria y no busca dilatar el procedimiento. De esta forma, mediante la utilización de remedios alternativos, se cumpliría al mismo tiempo con el principio de igualdad de las partes de la relación jurídica tributaria, se preservaría la recaudación y, lo más importante, se reconocerían así los derechos fundamentales de los ciudadanos" (Fernando Rosso, El solve et repete en el derecho tributario argentino: problemas y soluciones posibles, en http://imgbiblio.vaneduc.edu. ar/fulltext/files/TC051174.pdf, consultado el 15 de marzo de 2012, p. 107). 
por esta vía, a cumplir en tiempo oportuno la obligación pecuniaria resultante del proceso de liquidación, sin embargo, este pago no puede ser considerado como parte de las arcas fiscales hasta tanto no se resuelva la controversia, la que debe ser a favor del fisco para que efectivamente pueda este disponer de la suma previamente depositada por el contribuyente.

Por tal motivo, compartimos la postura adoptada por Pugliese, para quien la justificación política del solve et repete no satisface, ni tampoco responde a la realidad de las cosas, pues no es verdad que si no existiera este precepto los ingresos fiscales del Estado quedarían al arbitrio de la buena o de la mala voluntad de los contribuyentes, los cuales, con maliciosas oposiciones, podrían retrasar su recaudación, ya que no hay ninguna conexión necesaria entre la oposición promovida por el contribuyente y la suspensión de los actos ejecutivos para el cobro del tributo discutido. ${ }^{30}$

\subsubsection{Tesis fiscal o tributarista}

Esta tesis resulta ser una derivación de la anterior, toda vez que basa su fundamento en la necesidad de proteger la política de finanzas públicas establecida por el Estado. Aparece así el solve et repete como un privilegio o beneficio exclusivo de la hacienda pública, justificado por la importancia del interés público que el legislador ha entendido tutelar y del contenido particular del acto administrativo/tributario.

Entre sus defensores podemos encontrar al italiano Gustavo Ingrosso, quien sostuvo que el solve et repete "es el medio adecuado para el cumplimiento de la función normal de la Ley Tributaria, y la certeza de la percepción regular de los ingresos". ${ }^{31}$ En la misma dirección apunta Mordeglia, quien señala que el pago previo es

... una exigencia especial de los principios del Derecho Financiero o de las finanzas públicas, en el sentido de la vinculación que existe entre los recursos del Estado y los gastos públicos y la necesidad de que la percepción de las rentas tributarias, que son la principal forma de satisfacción de estos últimos, cuando no la única que refleja el equilibrio presupuestario, no pueda verse perjudicada mediante apelaciones $\mathrm{u}$ otros Recursos procesales. ${ }^{32}$

Como se puede apreciar, este fundamento fiscal o tributarista que se le ha querido conferir al solve et repete parte de la justificación política explicada supra, de ahí que las críticas a esta tesis tengan por base razones similares a las ya ale- 
gadas. Concebir al pago previo como un medio tendente a tutelar los créditos fiscales y, por ende, a garantizar el normal desenvolvimiento de la actividad financiera, particularmente durante la captación de fondos públicos a través del cobro de tributos, tampoco constituye una razón válida -en nuestra opinión- para continuar con el uso de esta regla que sigue siendo hoy un "arma en las manos del Fisco para reforzar su propia posición", 33 "una garantía en favor del Estado"; $; 3$ en fin, "un requisito esencialmente anacrónico y prácticamente inútil, que pretende tan solo resultados prácticos, y cuya fragilidad se revela desde la propia experiencia cotidiana"..$^{35}$

\subsubsection{Tesis iusprocesalista o prejudicial}

Adoptando una posición iusprocesalista, parte de la doctrina ha calificado al solve et repete como un presupuesto procesal, cuyo quebrantamiento impide que nazca la relación procesal, el cual es considerado un presupuesto de la acción. Bajo el manto de esta propia postura, otro grupo de seguidores ven en esta regla a una excepción procesal, que no constituye presupuesto de la acción procesal, sino una condición para que el juez pueda conocer el fondo del asunto. Así, en un intento de síntesis del contenido de esta tesis, nos refiere García de Enterría que "el solve et repete tiene dos manifestaciones: la admisión puramente formal del recurso se condiciona, o bien al pago total de la multa cuya legalidad va a discutirse, o bien al depósito, total o parcial de su cuantía por el recurrente" ${ }^{36}$

Entre los defensores de la primera vertiente de esta teoría podemos encontrar a Tribiño, quien reconoce al pago previo como un requisito o condición de admisibilidad de la acción contencioso-administrativa. Considera que esta regla, en el ámbito procesal administrativo, se traduce en que

... la impugnación judicial contra ciertas decisiones administrativas que determinan créditos del Estado contra particulares, solo puede efectuarse mediante el pago previo de las sumas respectivas, es decir, si no se abonan los importes en cuestión, el juez no puede entrar a conocer los aspectos de fondo de la pretensión del particular. ${ }^{37}$

33 Enrico Allorio, Diritto processuale tributario, 5 ed., Turín, 1969, p. 617.

34 Serrano Guirado, "El requisito del previo pago en el recurso contencioso-administrativo en materia fiscal", Revista de Derecho Financiero 5, 1952, p. 7.

35 Rafael Mendizábal Allende, "Significado actual del principio 'solve et repete'", op. cit., pp. 121 y 153. En opinión de este autor "la exigencia del pago previo no resulta precisamente el medio más idóneo ni tampoco el más noble y es, desde luego, el menos adecuado en un Estado de Derecho o de Justicia". En tal sentido refiere que "resulta preferible evitar la necesidad de recurrir en vez de impedir u obstaculizar esta facultad cuando tal necesidad se ha producido por un defectuoso funcionamiento administrativo". Por tal motivo considera que "establecer con claridad la situación del ciudadano frente a la Administración y procurar la más completa formación técnica y moral del funcionario público, con exigencia de una efectiva responsabilidad, evitando en lo posible que tenga excesivo interés en la cuantía de la deuda tributaria o de la sanción impuesta, resultan medios más eficaces y adecuados que el intento de compensar las deficiencias de la organización administrativa a costa siempre del ciudadano".

36 Eduardo García de Enterría, Curso de derecho administrativo, t. II, Madrid, Civitas, 1992, p. 195.

37 Carlos R. Tribiño, "El Solve et Repete en el Proceso Contencioso Administrativo", en Procedimiento y proceso administrativo. Jornadas organizadas por la carrera de Especialización en Derecho Administrativo Económico. 
Por su parte, Giannini es uno de los tratadistas que defiende la segunda vertiente de esta tesis, al calificar al solve et repete de excepción procesal. En tal sentido, alude que

... el interés del Estado en obtener el pago y en servirse de medios de coerción a tal objeto, tiene por órgano a la Administración y no el juez; por tanto, si la Administración no alega la excepción de falta de pago, el juez no puede apreciarla de oficio. De tal manera constituye siempre una excepción procesal, sin posibilidad de que sea apreciada de oficio por el juez si la Administración omite alegarla. ${ }^{38}$

De acuerdo con estos planteamientos, según esta tesis, la exigencia y aplicación del solve et repete se justifica por ser este un privilegio procesal, que necesariamente implica un condicionamiento de la admisibilidad de los reclamos administrativos o las acciones contencioso-administrativas en contra de multas $\mathrm{u}$ otras obligaciones dinerarias declaradas a favor de la Administración, al pago previo de esta por parte del particular afectado. Representa así un requisito necesario y exigido por ley para que pueda llevarse a cabo un proceso y que este goce de validez, lo que conlleva la exigencia de realizar el pago de todo el valor determinado por la Administración Tributaria para poder acceder a la justicia y discutir ante la autoridad la procedencia o validez del acto de determinación.

No compartimos tampoco esta posición doctrinaria, puesto que concebir al pago previo como presupuesto de admisibilidad de la acción o como requisito para poder interponer las demandas o los recursos posibles ante los tribunales, trae consigo una inversión en el proceso de conocimiento, por el cual se impone el pago del tributo antes de que se decida si este es pertinente, lo que invierte las habituales normas del proceso que hacen preceder el juicio de ejecución..$^{39}$ Por tal motivo, al colocar en primer lugar la ejecución, con anterioridad al proceso y la sentencia judicial, se altera el debido proceso legal e impide, a los contribuyentes cuyas condiciones económicas hacen imposible el pago previo del tributo, el acceso a la protección judicial de sus derechos. De tal forma se estaría privando al sujeto pasivo de la relación jurídico-tributaria de su derecho a revisar los actos de la Administración cuando soliciten un pronunciamiento sobre la legitimidad del acto administrativo que le impone una obligación a su juicio ilegal; se obstaculiza, asimismo, el acceso a la garantía que representa la intervención de la figura del juez, como sujeto imparcial, en este tipo de conflicto que da vía libre a la Administración Tributaria para decidir sobre la legalidad de sus propios actos. ${ }^{40}$ En fin, tal y como nos alerta Giulaini Fonrouge, "si se aplicase esta regla como requisito procesal se viola-

Facultad de Derecho. Departamento de Posgrado y Extensión Jurídica. Pontificia Universidad Católica Argentina, 2005, p. 443.

38 Giannini, Instituciones de derecho tributario, op. cit., pp. 259-260.

39 Jarach, Estudios de derecho tributario, op. cit., p. 282.

40 Bencomo Fariñas, "Solve et repete vs. tutela judicial en Cuba", op. cit., p. 8. 
ría el más elemental derecho de defensa, equivaldría a que se aplique la pena primero para luego juzgar su legalidad". ${ }^{41}$

\subsubsection{Tesis administrativista}

Considerada por gran parte de tratadistas en la doctrina como la única con real fundamento jurídico, la tesis administrativista parte de la presunción de legitimidad y del principio de ejecutoriedad de los actos administrativos para justificar la exigencia del solve et repete.

Esta teoría, única con importancia científica en opinión de Pugliese, fue analizada, entre otros, por Mortara, según el cual el solve et repete no es sino "una modalidad particular que los principios de legitimidad y ejecutoriedad de los actos administrativos toman en el Derecho Tributario, que tienen por corolario la prohibición hecha a la autoridad judicial de revocar o modificarlos, aunque los considere lesivos del derecho subjetivo del ciudadano". ${ }^{42}$ Del acto administrativo -nos refiere Pugliese-

... emana una presunción de legitimidad que, por una parte, no permite al magistrado atacar de ninguna manera la validez y la ejecutividad del acto mismo, y, por otra, vincula el sujeto pasivo, al cual está dirigida la orden contenida en el acto, para que la obedezca incondicionalmente. Por consiguiente, si el magistrado pudiera suspender la eficacia de las listas de pago antes de que el tributo en ellas indicado se pague, vendría a atacar la ejecutoriedad del acto administrativo y a modificarlo directamente, lo que le está prohibido; mientras que, en virtud del precepto de solve et repete, cuando la orden administrativa sea ejecutada, y el tributo pagado, no hay obstáculo para que el magistrado conozca de sus efectos, y en caso dado, los anule ordenando la restitución de lo que el fisco ha cobrado basándose en un acto ilegítimo. ${ }^{43}$

Bielsa y Jarach son también partidarios de esta posición. Sostuvo el primero que

la regla solve et repete encuentra su sustento jurídico en la presunción de legitimidad y de ejecutoriedad de los actos administrativos, de los que se derivaría la procedencia de no suspender los efectos de una determinación impositiva hasta que se abone el tributo o se logre su revocación en sede judicial. ${ }^{44}$

Jarach, por su parte, trata a la regla como equivalente al efecto que de la ejecutoriedad se deriva, a saber, la no suspensión del pago del tributo, determinado por la autoridad administrativa, por la iniciación de una demanda o recurso ante la autoridad jerárquica superior o pasar de la esfera administrativa a la judicial; afirma, entonces, que "el instituto del pago previo es el medio escogido por el legislador para que el principio de ejecutoriedad del acto administrativo/tributario se manifieste plenamente". ${ }^{45}$ 
De los criterios precedentes podemos apreciar que los expositores de esta tesis fundamentan el reconocimiento y la exigencia de la regla tomando como referente a pilares del régimen administrativo: la presunción de legitimidad y el principio de ejecutoriedad. Ello significa que al acto de determinación tributaria, como modalidad de acto administrativo, le asiste una presunción de legitimidad y es por lo mismo ejecutorio ${ }^{46}$ de modo tal que la ley prohíbe juzgar controversias impositivas antes de que la pretensión tributaria haya sido satisfecha, ya que presupone que el acto de fijación del tributo es legítimo, lo que trae como consecuencia inmediata de esta presunción el denominado privilegio de la decisión ejecutoria o beneficio de la declaración previa y, abreviadamente, ejecutoriedad.

Si bien a esta tesis, por una parte, se le puede destacar como elemento positivo el hecho de explicar al solve et repete sobre la base de fundamentos propiamente jurídicos, por otra denota una importante interrogante: ¿ejecutoriedad o tutela judicial efectiva?

En opinión de Guerra Reguera nos encontramos así ante una nerviosa tensión entre dos principios encontrados. Si la balanza se inclinase decididamente por la suspensión del acto tras la interposición de un recurso, se originaría un serio perjuicio a los intereses públicos por la inoperancia a la que quedaría condenada la Administración. Por el contrario, si se abogase por una ejecutoriedad inquebrantable, muchas situaciones quedarían injustamente alteradas sin posibilidad de una reconstrucción verdaderamente convincente. La solución a este dilema es -nos indica este autor- "una cuestión de equilibrio, consistente en la posibilidad de suspender la ejecución del acto administrativo cuando concurran determinadas circunstancias". ${ }^{47}$ La suspensión se convierte, así, en una medida tendente a mitigar el efecto de las prerrogativas administrativas y atenuar un tanto la amplia capacidad de actuación de la Administración en la ejecución de los actos administrativos, en caso de impugnación.

Al igual que otros autores que de plano rechazan esta tesis administrativista, ${ }^{48}$ no concordamos con sus postulados para defender la exigencia del solve et repete en la esfera tributaria. Ténganse en cuenta que la posibilidad de revisión

Bencomo Fariñas, "Solve et repete vs. tutela judicial en Cuba", op. cit., p. 9.

Manuel Guerra Reguera, Suspensión de actos administrativos tributarios, Granada, Comares, 1999, pp. 8-14.

A modo de ejemplos se pudiera citar a Mendizábal Allende, para quien "la presunción de legitimidad constituye, eso sí, su perímetro o fundamento negativo, puesto que resultaría inconcebible e inicuo exigir el pago previo de la cantidad controvertida si no se partiera de tal apariencia de legalidad. Pero en el aspecto procesal, la presunción implica, exclusivamente, la inversión permanente de la posición de la Administración Pública, que en todo caso habrá de ser demandada, por lo que corresponderá siempre al particular la carga de impugnar su actuación [...]. Tampoco el principio de la ejecutoriedad de los actos administrativos sirve para ofrecer un sólido pedestal a la regla solve et repete. De aquél deriva, en efecto, la imposibilidad de que el Juez administrativo suspenda o paralice la acción ejecutiva para la recaudación del tributo o de la sanción. De esta forma pone de relieve la mutua independencia del proceso judicial y del procedimiento administrativo de apremio, pero nunca puede significar que la pretensión contencioso-administrativa no deba ser siquiera examinada por el Juez sin el pago previo" (Mendizábal Allende, "Significado actual del principio 'solve et repete"', op. cit., pp. 151-152). Igualmente, Perulles estima que "la necesidad del pago previo es in- 
judicial del acto de determinación tributaria sin exigir el pago previo de la prestación no subvierte la presunción de legitimidad del acto administrativo ni inhibe su fuerza ejecutoria. Recordemos que una de las principales consecuencias que se desprende de la ejecutoriedad del acto administrativo es que debe, por principio, ejecutarse a pesar de la interposición de recursos contra él; es decir, que la interposición de recursos contra el acto no suspende su ejecución, de ahí que la exigencia del pago previo no tendría razón de ser si lo que se quiere es evitar que se suspenda la ejecución de lo dictaminado por la Administración Tributaria, puesto que la mera interposición de una reclamación no es óbice para que el acto administrativo/tributario deje de desplegar sus efectos.

Además, admitir la presunción de legitimidad en forma amplia -nos alerta Gordillo- "lleva a la consecuencia de proteger la arbitrariedad administrativa, facilitar el exceso y dificultar la efectiva vigencia de los derechos de los individuos". ${ }^{49}$ Por otra parte, abogar por el sostenimiento del solve et repete como una manifestación particular de la ejecutoriedad del acto administrativo implica una reduplicación de los medios ejecutivos de la administración, así como a una desnaturalización del ejercicio de la función jurisdiccional, por lo que se conculca de tal modo el derecho de toda persona a la tutela judicial efectiva. Tal situación se torna, según Spisso, "inconstitucional", toda vez que "en un Estado de Derecho [...] resulta inadmisible la obligación de pago sin que exista la posibilidad de que un Tribunal de Justicia evalúe siquiera la procedencia"; $;{ }^{\prime 5}$ de ahí que la ejecución forzosa de la deuda tributaria deba hacerla la Administración, sin coartar la acción de defensa jurídica del obligado al pago.

Esta tesis, por tanto, resulta criticable, pues este argumento de presunción de legitimidad y ejecutoriedad del acto administrativo fiscal, por sobre el control judicial, daría lugar a grandes atropellos por parte de la Administración Tributaria, lo que atenta contra derechos y principios reconocidos y protegidos constitucionalmente a lo largo de los años.

\subsubsection{Tesis autónoma}

Esta corriente doctrinaria concibe al solve et repete como un instituto propiamente fiscal, con fundamentos económicos, políticos y culturales, cuyos seguidores defienden la tesis de que estamos ante una regla peculiar del derecho tributario, cuya finalidad es impedir al contribuyente -que no haya cumplido con el pago previo del tributo- que pida en juicio la tutela de su derecho; con lo cual se ejerce sobre él una presión para obligarlo a cumplir, en tiempo oportuno, la obligación resultante de la liquidación.

dependiente de la fuerza ejecutiva del acto de determinación del impuesto" (J. J. Perulles, La relación jurídico tributaria, Barcelona, 1957, pp. 389-390).

49 Agustín A. Gordillo, Tratado de derecho administrativo. El acto administrativo, Bogotá, 1999, pp. 19-28.

50 Rodolfo Spisso, Tutela Judicial efectiva en materia tributaria, Buenos Aires, Depalma, 1996, p. 89. 
Entre sus defensores podemos encontrar a Griziotti, quien afirma que el solve et repete

... constituyeuna institución autónoma delDerecho Financiero[...] que protegelas finanzas públicas, erigiendo una valla para los contribuyentes de mala fe; desalentando así la promoción de acciones infundadas o temerarias de los obligados que puedan impedir el regular ingreso de los tributos en la arcas estatales para cumplir con sus fines públicos. ${ }^{51}$

De esta forma rechaza todo concepto extraño al derecho financiero, particularmente al derecho tributario, manifestando que el requisito del pago previo consiste en una medida protectora de la política financiera que evita que se trabe el accionar de la Administración.

Esta tesis, como las anteriormente expuestas, carece también de un fundamento sólido que demuestre la necesidad del reconocimiento legal y consecuente exigibilidad del solve et repete; en este caso, la crítica está dirigida al hecho de que el requerimiento del pago previo no es un elemento propio y exclusivo del derecho tributario, pues se reconoce y aplica en otras cuestiones, como ocurre en la facturación de los servicios de luz, gas, teléfono, etc.; donde los usuarios deben abonar sus facturas para poder luego reclamar ante el órgano administrativo correspondiente.

\subsubsection{Unión de dos o más tesis}

Adoptando una postura que pudiésemos denominar "ecléctica", algunos autores conjugaron las notas características de las tesis ya expuestas para justificar al pago previo.

De todas las posiciones que en la doctrina se defendieron como fundamento del solve et repete, podemos encontrar, entre las más unificadas, a las teorías política y administrativista. Entre sus sostenedores se encuentra De Benedetti, quien entiende que "dicha regla se encuentra íntimamente relacionada con la ejecutoriedad de los actos administrativos y su presunción de legitimidad, dirigida a asegurar un constante flujo de ingresos al ente recaudador para que este se encuentre en condiciones de afrontar el mantenimiento del sistema previsional". ${ }^{52}$ Asimismo, Martín Oviedo nos refiere como ejemplo la jurisprudencia del Tribunal Supremo italiano, particularmente la sentencia de 13 de marzo de 1941, en la que se indica que "el principio solve et repete tiene por fin asegurar la pronta exacción del tributo y se justifica, políticamente, por la necesidad de dar puntual cumplimiento a las obligaciones tributarias y, jurídicamente, por razón de la ejecutoriedad del acto administrativo". ${ }^{53}$

52 María I. De Benedetti., "Solve et repete la faz previsional". Cit. pos. Juan S. Vela Mariño, Inconstitucionalidad del solve et repete, en http://repositorio.usfq.edu.ec/bitstream/23000/1079/1/95178.pdf, p. 25, consultado el 27 de marzo de 2012.

53 Martín Oviedo, "La decadencia de la regla solve et repete y la doctrina del Consejo de Estado", op. cit., p. 153. 
Otros autores armonizan, además de las expuestas, otras tesis. Tesoro, por ejemplo, manifiesta que "la regla es una norma particular de nuestra rama del derecho, justificada, en parte, por necesidades políticas y por la presunción de legitimidad del acto administrativo de determinación, pero sustancialmente diversa y paralela al principio de la ejecutoriedad", ${ }^{54}$ para unir, de esta forma, las teorías administrativista, política y autónoma a fin de fundamentar al solve et repete.

Barreiro, por su parte, explica la exigencia del pago previo tomando como referente las tesis autónoma y fiscal, al señalar que "se trata de un instituto específico del Derecho Tributario con características propias, que lo alejan del Derecho Administrativo general, cuya justificación se encuentra en su carácter de instrumento útil a la tutela de los intereses patrimoniales del fisco". ${ }^{55}$

Brewer, al referirse a la regla, declara que se trata, en efecto, de

... una derivación práctica de la no suspensión del acto administrativo, sin fundamento jurídico sólido alguno, y cuya finalidad consiste en garantizar drásticamente y sin piedad la recaudación de los tributos, como también la presión directa de las sanciones administrativas, actuando en defensa de los intereses inmediatos de la Administración Pública [...] Su efecto fundamental es, por otra parte, constituir un requisito de admisibilidad de los recursos gubernativos y contencioso-administrativos. ${ }^{56}$

Así quedan conjugadas las tesis administrativista, política e iusprocesalista.

De más está precisar que si no compartimos los fundamentos expuestos en cada una de las tesis explicadas supra, tampoco consideramos acertada esta posición que acude a mezclar los argumentos ya defendidos por otras teorías de la doctrina para intentar razonar la virtualidad práctica de una regla que progresivamente está llamada a fenecer.

Llegados a este punto, resulta dable reafirmar que estamos en total desacuerdo con los argumentos expuestos en cada una de las tesis analizadas, que para nada están acordes con las tendencias del derecho tributario moderno, toda vez que las normas tributarias hoy día están llamadas a no orientarse exclusivamente a la defensa del crédito tributario y a la protección de la Administración acreedora.

En todo caso, después del estudio de normas tributarias, es nuestro criterio, el solve et repete se configura como una regla de carácter procesal que comporta, para el contribuyente, la exigencia del pago previo de lo exigido por la Admi-

\footnotetext{
54 Tesoro, Principi di diritto tributario, op. cit., p. 437.

55 Rafael Barreiro, Algunas reflexiones sobre la constitucionalidad del solve et repete, t. Impuestos 49, Argentina, La Ley, 1991, p. 106.

56 Brewer C., Aspectos de la ejecutividad y ejecutoriedad de los actos administrativos fiscales y la aplicación del principio "Solve et Repete", op. cit., p. 24.
} 
nistración Tributaria como requisito para poder impugnar los actos administrativos/tributarios -que involucren la liquidación de un crédito-mediante la interposición del correspondiente Recurso, ya sea en la propia fase administrativa o para iniciar un proceso ante la jurisdicción contencioso-administrativa. Sin embargo, más allá del argumento o fundamento que se le quiera atribuir para continuar con su exigencia en el ámbito fiscal, lo que realmente importa y trasciende son las consecuencias que de esta figura surgen en la práctica, las cuales crean para el sujeto pasivo de la relación jurídico-tributaria que esté en desacuerdo con lo resuelto por la Administración Tributaria, un obstáculo en el ejercicio de su derecho de defensa, dado que se le priva del acceso a la justicia, situación que desencadena a la par el resquebrajamiento de otros importantes derechos, cuya protección y salvaguarda deben ser garantizadas en cualquier sistema jurídico.

\section{La regla solve et repete y su incidencia en derechos y principios constitucionalmente reconocidos}

La doctrina más conspicua ha sostenido durante los últimos tiempos la idea visceral que destaca la necesidad de la inmediata aniquilación de la exigencia de la regla solve et repete en materia fiscal, toda vez que se trata de un "fatídico resabio absolutista [...] en cuyo enunciado se revela la barbaridad jurídica que implica, y su brutal contrariedad con el respeto más elemental de los derechos fundamentales de la persona humana", ${ }^{57}$ al exigir el cumplimiento de la sanción antes que pueda ser reclamada o impugnada.

Lamentablemente, queda aún mucho camino por recorrer hasta extinguir los supuestos legales de solve et repete actualmente vigentes e impedir que puedan volver a renacer o reproducirse en el futuro, tarea esta que corresponde, desde luego, al legislador, pero no en menor medida a la doctrina científica y jurisprudencial. Ante esta realidad resulta pertinente ahondar en algunas de las afectaciones que conlleva la exigencia del pago previo para el contribuyente, aludiendo a tales efectos la vulneración que el reconocimiento y aplicación de esta regla genera en derechos y principios constitucionalmente reconocidos.

Al quedar configurada la regla solve et repete como presupuesto de admisibilidad de la acción obstaculiza, en primer lugar, un derecho de tamaña magnitud: el derecho de acceso a la justicia, también denominado por la doctrina española como derecho a la tutela judicial efectiva. Así lo han postulado autores como Valdés Costa, quien categóricamente refiere que "el mantenimiento de esta regla hace ilusoria la tutela jurisdiccional" ${ }^{58}$ Ciertamente, vedar el acceso a la

57 Soto Kloss, "El solve et repete. Notas sobre un resabio absolutista en el Estado constitucional de derecho", Revista Ius Publicum 6 (2001), p. 82.

58 Valdés Costa, El contencioso tributario, op. cit., p. 53. 
justicia es una afectación grave, pues se trata de un derecho fundamental por medio del cual se le da contenido material a la igualdad mediante la exigibilidad de otros derechos y la resolución de conflictos entre particulares o entre estos y el Estado. Por lo mismo, el acceso a la justicia es concebido como una especie de derecho bisagra, en cuanto permite dar efectividad a los restantes derechos, lo que abre el camino para reclamar por su cumplimiento y así garantizar la igualdad y la no discriminación. El acceso a la justicia determina, por tanto, las posibilidades de defensa de los derechos humanos, y constituye a la par un requisito para la auténtica garantía jurídica de los mismos.

El tema del acceso a la justicia es consustancial también a la seguridad jurídica, de ahí que cuando analizamos los obstáculos que se hallan en el camino del primero estemos determinando de igual modo los elementos o figuras atentatorias de la segunda.

\section{Al decir de Ferrari Yaunner,}

... la seguridad, para ser alcanzada como fin del Derecho, no debe conformarse con la sola existencia de un sistema normativo que oriente a los hombres qué no hacer, qué hacer y cómo hacerlo. Desde el punto de vista formal esto pudiera ser suficiente, sin embargo, la práctica social demuestra que, si el Derecho no se realiza plenamente y las normas no son respetadas por toda la sociedad, si los ciudadanos no cuentan con verdaderas garantías eficaces para sus derechos, la seguridad se convierte en un discurso político y nadie sentirá su presencia. ${ }^{59}$

\section{$\mathrm{Al}$ respecto nos ilustra Cutié Mustelier que}

... hoy día, para un amplio sector de la doctrina Constitucional, las garantías jurisdiccionales son los medios idóneos para la protección de los derechos humanos, al estar dotados de una serie de condiciones o cualidades que le permiten desempeñar con eficacia esta importante misión, pues en efecto, la sola posibilidad de acudir a un órgano imparcial e independiente [...] puede permitir a quien ve vulnerado o amenazado algunos de sus derechos humanos, obtener su protección o reparación con la consiguiente restitución en el pleno goce de su derecho o prevenir su violación inminente. ${ }^{60}$

Por tal motivo, al ser el solve et repete un requerimiento económico que hace depender de los recursos monetarios del contribuyente el acceso a los órganos jurisdiccionales, trae consigo ineluctablemente que se entorpezca además su seguridad jurídica, y lo coloca francamente en situación de indefensión frente a la Administración Tributaria cuando no posee los medios para cumplir con el pago previo.

59 Majela Ferrari Yaunner, "La seguridad jurídica y la legalidad: un estudio necesario", en Andry Matilla Correa (coord.), Panorama de la ciencia del derecho en Cuba. Estudios en homenaje al profesor Dr. C. Julio Fernández Bulté, La Habana, Facultad de Derecho, Universidad de La Habana, 2009, pp. 229-235.

60 Danelia Cutié Mustelier, El sistema de garantías de los derechos humanos en Cuba (tesis doctoral), Santiago de Cuba, 2001, p. 38. 
Y es que no debemos olvidar que la seguridad jurídica es un componente fundamental de la posición del ciudadano frente al poder del Estado, pero no porque frente a la actividad tributaria deba predicarse una seguridad especial, como contrapunto de un pretendido status subiectionis del contribuyente, sino porque la seguridad jurídica es un componente esencial de la posición del ciudadano en todas sus relaciones con el Estado y también, obviamente, en sus relaciones tributarias. ${ }^{61}$ La seguridad jurídica se manifiesta así como un peldaño previo para alcanzar la justicia, de ahí que sea inaceptable el establecimiento de obstáculos injustificados que socaven su consecución plena. El solve et repete atenta, además, contra el principio de igualdad. En tal sentido, nos manifiesta Cassagne que

... lo esencial de la igualdad radica en la garantía que tienen los administrados para impedir que se estatuyan en las leyes, reglamentos y aun en los actos singulares o concretos de aplicación de normas generales, distinciones arbitrarias o fundadas en propósitos de hostilidad contra personas o grupos de personas o que importen el otorgamiento indebido de privilegios. ${ }^{62}$

No podemos olvidar que, como bien afirma Gordillo, "una norma legislativa o reglamentaria irrazonable, disvaliosa, desviada, persecutoria [...] es inconstitucional y como tal debe ser anulada o inaplicada en los casos ocurrentes". ${ }^{63}$ Por tal motivo, serán inaplicadas o declaradas inconstitucionales aquellas disposiciones de la Administración Pública que sean lesivas al principio constitucional de igualdad $y$, consecuentemente, generen un trato discriminatorio.$^{64}$

En opinión de Tapia, la idea central que informa al principio de igualdad en el derecho tributario es la exclusión de las relaciones de poder, y no es exacto afirmar que en la relación obligatoria de naturaleza impositiva el acreedor se encuentre en una posición de preeminencia jurídica sobre el deudor. Ciertamente, el Estado no comparece en este proceso como titular de un poder estatal, sino como un acreedor más, titular de un derecho personal, que busca la tutela de su interés económico. El fisco, en ejercicio de la función administrativa, solo puede estimular, incentivar, exhortar, incluso amenazar al contribuyente para que cumpla con sus deberes impositivos; pero en casos de resistencia de este le está vedado satisfacer coactivamente su pretensión. En ese momento -agotados infructuosamente los medios administrativos tendentes a la satisfacción de su pretensión tributaria- el fisco está obligado a pedir al poder judicial, como parte -en igualdad de condiciones con la otra parte, el ciudadano-contribuyente-deudor- que conozca, decida y ejecute su pretensión. Sostiene además que "la igualdad como principio excede el marco de la 
relación jurídica tributaria principal para vincularse estrechamente y encontrar su concreción en dos principios conexos, con los cuales prácticamente se identifica: la legalidad, en el derecho material y administrativo tributario; y la tutela judicial efectiva, en el derecho procesal" ${ }^{65}$

Desde el punto de vista de la relación obligatoria y como una consecuencia lógica de ella, la igualdad se vincula a la relativa posición en que se encuentran las partes dentro de la obligación tributaria, que es infringida por la exigencia del pago previo en dos facetas: la procesal y la económica. ${ }^{66}$

En la esfera procesal destruye el inestable equilibrio de las partes litigantes. La posición de supremacía de la Administración Pública, que, como gráficamente se ha dicho, por mucho que consienta en agacharse es siempre un gigante, y sus inmediatas consecuencias (presunción de legitimidad y potestad ejecutoria), se ve reforzada por el solve et repete, obstáculo defensivo de gran envergadura. En la esfera económica, por su parte, supone una discriminación en perjuicio de los económicamente débiles, pues solo aquellos contribuyentes que pueden afrontar el pago previo son los que podrán discutir en un proceso posterior la causa de la obligación tributaria, mientras que los restantes serán sometidos a la ejecución fiscal sin posibilidad de acudir ante un órgano imparcial que dictamine sobre su caso.

Ante este escenario, justo es reconocer que dotar de una mayor protección jurídica al obligado tributario ante el actuar de la Administración Tributaria continúa siendo un reclamo jurídico. La regla solve et repete debe ser desterrada de los ordenamientos procedimentales tributarios en los que sigue vigente, sobre todo, porque restringe el acceso del contribuyente a la jurisdicción contencioso-administrativa y, por ende, constituye un obstáculo al ejercicio del derecho fundamental de tutela judicial efectiva. Como consecuencia, transgrede la seguridad jurídica, quebranta el principio de proporcionalidad y la razonabilidad normativa, profana también el estado jurídico de inocencia del que goza todo ciudadano al implicar una flagrante violación al derecho de defensa. La exigencia del pago previo vulnera además la igualdad, lo que en la práctica se configura como traba u obstáculo procesal que pone en una situación de clara indefensión al contribuyente que quiera hacer valer sus derechos e intereses legítimos y que no cumpla con el requerimiento económico que esta regla comporta. ${ }^{67}$

65 Tapia C., "Bases para un debido proceso tributario: tres teorías acerca de la relación entre el Estado y los contribuyentes", Revista Chilena de Derecho 32 (2) (2005), pp. 332-345, en https://www.redalyc.org/articulo. oa?id=177021336006

66 Mendizábal Allende, “Significado actual del principio ‘solve et repete"', op. cit., pp. 154-155.

67 Bencomo Fariñas, "Solve et repete vs. tutela judicial en Cuba", op. cit., pp. 21-22. 


\section{Conclusiones}

El solve et repete ha generado múltiples debates en la doctrina y una extensa jurisprudencia en el entorno tributario. Al respecto se han alzado voces de importantes tratadistas ya sea para, por un lado, defender el mantenimiento de esta regla procesal o, por el otro, para justamente abogar por su supresión ante las negativas consecuencias que, en el orden de la protección jurídica del sujeto pasivo, este instituto acarrea.

Ciertamente, no existe una posición uniforme en la doctrina cuando se intenta desentrañar las razones que sirven de fundamento a la exigencia del pago previo en el ámbito tributario. Sin embargo, en las tesis defendidas podemos encontrar como denominador común el hecho de concebir al solve et repete básicamente como una herramienta que, en manos de la Administración Tributaria, garantiza el cobro puntual de los tributos, de forma tal que se lleve a cabo la actividad financiera del Estado sin dilaciones innecesarias.

Cualquiera que sea el argumento aportado en su defensa, estamos en total desacuerdo, toda vez que la exigencia legal y práctica del pago previo hace nulo el poder ejercitar derechos reconocidos en la Constitución, lo que deja al sujeto pasivo de la relación jurídico-tributaria, y en particular al contribuyente, en un real estado de indefensión.

Así, anteponiendo el principio de eficacia recaudatoria, y reforzando el carácter ejecutivo y ejecutorio del acto administrativo en materia tributaria, el requerimiento del pago previo violenta el derecho a la tutela judicial efectiva que conlleva, per se, el libre acceso a la administración de justicia, con observancia de un debido proceso y con la certeza de la eficacia de las sentencias. Asimismo, menoscaba la igualdad, el derecho de defensa, el patrimonio del contribuyente, así como los principios de seguridad jurídica, gratuidad de la justicia y presunción de inocencia; razones todas que han motivado el rechazo a esta regla e, incluso, que en varios ordenamientos jurídicos haya sido declarada inconstitucional; de ahí que su eliminación progresiva, sin lugar a dudas, coadyuve a que se evolucione hacia un sistema tributario más justo, que atienda tanto a los intereses estatales como a los de los sujetos pasivos.

En tal sentido, la tarea más compleja sigue siendo lograr una revolución en las mentes, una ruptura de etiquetas y esquemas, en fin, borrar prejuicios heredados con mucho arraigo y transmitidos de generación en generación, tal y como ocurre con el solve et repete.

\section{Referencias}

Alexy, Robert, "Sistema jurídico, principios jurídicos y razón práctica", Revista Doxa 5 (1988). DOI: https://doi.org/10.14198/DOXA1988.5.07 
Allorio, Enrico, Diritto processuale tributario, 5 ed., Turín, 1969.

Atienza, Manuel y Juan Ruiz Manero, "Sobre principios y reglas", Revista Doxa 10 (1991). DOI: https://doi.org/10.14198/DOXA1991.10.04

Barreiro, Rafael, Algunas reflexiones sobre la constitucionalidad del solve et repete, t. Impuestos 49, Argentina, La Ley, 1991.

Bencomo Fariñas, Yaneisi, "Solve et repete vs. tutela judicial en Cuba: tema pendiente en el Derecho Procesal Constitucional", Revista Mexicana de Derecho. Constitucional Cuestiones Constitucionales 28 (2013), pp. 3-33.DOI: http://dx.doi.org/10.1016/S1405-9193(13)71274-5

Bielsa, Rafael, Estudios de derecho público, t. II, Derecho fiscal, Buenos Aires, Depalma, 1951.

Billardi, Cristian, Solve et Repete. Crítica a su vigencia jurídica, Buenos Aires, Editora Ad-Hoc, 2006.

Brewer Carías, Allan R., Aspectos de la ejecutividad y ejecutoriedad de los actos administrativos fiscales y la aplicación del principio "Solve et Repete", en http:// www.allanbrewercarias.com/Content/449725d9-f1cb-474b-8ab2-41efb849fea8/Content/II.4.25.pdf

Cassagne, Juan C., Derecho Administrativo, t. I, 8 ed., Buenos Aires, AbeledoPerrot, 2006.

Clavero Arévalo, Manual Francisco, "El problema del previo pago en la reciente jurisprudencia", Revista de Administración Pública 41 (1963), en https:// dialnet.unirioja.es/servlet/articulo? codigo $=2113080$

Convención Americana sobre Derechos Humanos de 1969 o Pacto de San José, en https://www.oas.org/dil/esp/tratados_b32_convencion_americana_sobre_derechos_humanos.htm

Cosculluela Montaner, Luis, Manual de derecho administrativo, t. I, 17 ed., Pamplona, Thomson Civitas, Aranzadi, 2006.

Declaración Americana de Derechos y Deberes del Hombre en 1948, en https://www.oas.org/dil/esp/Declaraci\%C3\%B3n_Americana_de_los_ Derechos_y_Deberes_del_Hombre_1948.pdf, consultado el 21 de agosto de 2014.

Declaración Universal de Derechos Humanos, en http://unesdoc.unesco.org/ images/0017/001790/179018m.pdf, consultado el 21 de agosto de 2014.

Ferrada Bórquez, Juan C., “Las potestades y privilegios de la Administración Pública en el régimen administrativo chileno", Revista de Derecho XX (2) (2007), en http://dx.doi.org/10.4067/S0718-09502007000200004 
Garrido Falla, Fernando, Tratado de Derecho Administrativo, t. I, 2 ed., Madrid, IEP, 1962.

Giannini, A. D., Instituciones de Derecho Tributario, Madrid, Editorial de Derecho Financiero, 1957.

Giuliani Fonrouge, Carlos M., "Acerca del solve et repete", Revista Jurídica Argentina, Buenos Aires, La Ley, 1990.

Giuliani Fonrouge, Carlos M., Derecho Financiero, vol. II, Buenos Aires, Editorial Depalma, 1976.

Giuliani Fonrouge, Carlos, Rubens Gómez De Sousa y Ramón Valdés Costa, Reforma Tributaria para América Latina III Modelo de Código Tributario, Washington D.C., Unión Panamericana Secretaría General, Organización de los Estados Americanos, 1968.

Gordillo Agustín A., Tratado de Derecho Administrativo. El acto administrativo, Bogotá, 1999.

Griziotti, Benvenuto, Principios de ciencia de las finanzas, Buenos Aires, Editorial Roque Depalma, 1959.

Guerra Reguera, Manuel, Suspensión de actos administrativos tributarios, Granada, Comares, 1999.

Hutchinson, Tomás, "El solve et repete en la Argentina (con especial referencia al Código Tributario de la Ciudad Autónoma de Buenos Aires)", Revista de Derecho Público, abril-junio, 2003, en http://sedici.unlp. edu.ar/bitstream/handle/10915/70229/Documento_completo.pdf-PDFA. pdf? sequence $=1 \&$ isAllowed $=y$

Ingrosso, Gustavo, Instituzioni di diritto finanziario, t. II, Napoli, Editorial Jovene, 1952.

Jarach, Dino, Estudios de derecho tributario, 3 ed., Buenos Aires, Abeledo-Perrot, 1998.

Martín Oviedo, José M., "La decadencia de la regla solve et repete y la doctrina del Consejo de Estado", Revista de Administración Pública 43 (1964).

Mendizábal Allende, Rafael, "Significado actual del principio 'solve et repete'", Revista de Administración Pública 43 (1964), en http://www.cepc.gob.es/ publicaciones/revistas/revistaselectronicas?IDR=1\&IDN=43\&IDA=22330

Modelo de Código Tributario propuesto por el CIAT en 1997, en http://www. unav.es/tributario/Documentos/modelo_codigo_tributario_1997.pdf, consultado el 21 de agosto de 2014. 
Pacto Internacional de Derechos Civiles y Políticos, en http://ccprcentre.org/ doc/HRC/Colombia/CCPR.C.COL.6.pdf

Perulles, La relación jurídico tributaria, Barcelona, 1957.

Pugliese, Mario, Instituciones de derecho financiero, México, Fondo de Cultura Económica, 1939.

Rosso, Fernando, El solve et repete en el derecho tributario argentino: problemas y soluciones posibles, en http://imgbiblio.vaneduc.edu.ar/fulltext/files/ TC051174.pdf

Santamaría Pastor, Juan A., "Un paso adelante en la extinción del solve et repete", Revista Española de Derecho Administrativo 2 (1974).

Serrano Guirado, "El requisito del previo pago en el recurso contenciosoadministrativo en materia fiscal", Revista de Derecho Financiero 5 (1952).

Simón Otero, Liana, "Los principios de justicia tributaria en la historia constitucional cubana", Revista Mexicana de Derecho Constitucional. Cuestiones Constitucionales 25 (2011), pp. 201-266, en http://dx.doi.org/10.22201/ iij.24484881e.2011.25.5971

Simón Otero, Liana, La protección del contribuyente en Cuba: una visión desde el Derecho Constitucional Tributario (tesis presentada en opción al título académico de máster en Derecho Constitucional y Administrativo), La Habana, 2011.

Spisso Rodolfo, Tutela Judicial efectiva en materia tributaria, Buenos Aires, Depalma, 1996.

Tapia C., "Bases para un debido proceso tributario: tres teorías acerca de la relación entre el Estado y los contribuyentes", Revista Chilena de Derecho 32 (2) (2005), en https://www.redalyc.org/articulo.oa?id=177021336006

Tesoro, Giorgio, Principi di diritto tributario, Bari, 1938.

Tribiño Carlos R., "El solve et repete en el proceso contencioso administrativo", en Procedimiento y proceso administrativo. Jornadas organizadas por la carrera de Especialización en Derecho Administrativo Económico, Facultad de Derecho, Departamento de Posgrado y Extensión Jurídica, Pontificia Universidad Católica Argentina, 2005.

Valdés Costa, Ramón, El contencioso tributario. Comunicación presentada a las "Segundas Jornadas Latinoamericanas de Derecho Tributario", efectuadas en México, D.F, en octubre de 1958.

Villegas, Héctor B., Curso de finanzas, derecho financiero y tributario, 7 ed., Buenos Aires, Depalma, 2001. 


\section{Jurisprudencia}

Código Orgánico Tributario de la República Bolivariana de Venezuela, de 17 de octubre de 2001, Gaceta Oficial 37.305.

Constitución de la República Bolivariana de Venezuela de 1999, Gaceta Oficial Extraordinaria 5.453, de 24 de marzo de 2000.

Constitución Española de 1978, en http://www.congreso.es/docu/constituciones/1978/1978_cd.pdf, consultado el 21 de agosto de 2014.

Decreto 308 Reglamento de las Normas Generales y de los procedimientos Tributarios, de 31 de octubre de 2012, Gaceta Oficial Ordinaria 53, de 21 de noviembre de 2012.

Ley 113 Del Sistema Tributario, de 23 de julio de 2012, Gaceta Oficial Ordinaria 53, de 21 de noviembre de 2012.

Ley 1307 de 5 de febrero de 2007 de la República Dominicana, reguladora del Tribunal Contencioso Tributario y Administrativo, en http://www. consultoria.gov.do/Documents/GetDocument?reference=84518abc-c363443a-89e9-f6ad5b208b4f

Ley 18.840 del Banco Central Chile, 10/10/1989.

Ley 189, Código Contencioso Administrativo y Tributario de la Ciudad Autónoma de Buenos Aires.

Ley 19.300 sobre Bases Generales del Medio Ambiente, 09/03/1994.

Ley 19.613, de modificación de la Ley 18.410, Orgánica de la Superintendencia de Electricidad y Combustibles

Ley 19549 de Procedimiento Administrativo de Argentina, en http://infoleg.mecon. gov.ar/infolegInternet/anexos/20000-24999/22363/norma.htm, consultado el 30 de junio de 2015.

Ley de Amparo, Reglamentaria de los artículos 103 y 107 de la Constitución Política de los Estados Unidos Mexicanos (DOF 10/01/1936).

Ley Federal de Procedimiento Administrativo del Estado de México (DOF 04/08/1994). 